\title{
A PRODUÇÃO DA COLETIVIDADE: OLHARES IMBRICADOS NA PRODUÇÃO DA COTUTELA NO PIBID-QUÍMICA DA UFPEL
}

\section{The production of the collective: integrated views in the production of the coworking in Chemistry PIBID of UFPEL}

\section{La producción del colectivo: miradas imbricadas en la producción de la cotutela en el PIBID-Química de la UFPEL}

\author{
Bruno dos Santos Pastoriza ${ }^{1}$ \\ Fábio André Sangiogo ${ }^{2}$ \\ Aurélia Valesca Soares de Azevedo ${ }^{3}$ \\ Karla dos Santos Terra ${ }^{4}$ \\ Sandriane Valadão Duarte 5 \\ Alex Sandro de Castro Garrido ${ }^{6}$ \\ Thaine Brede Mota $^{7}$ \\ Vanessa Lemos Guimarães ${ }^{8}$ \\ Vitória Schiavon ${ }^{9}$ \\ Tavane Rodrigues ${ }^{10}$
}

1 Autor. Doutor em Educação em Ciências, Docente do Magistério Superior, Universidade Federal de Pelotas. Laboratório de Ensino de Química, Centro de Ciências Químicas, Farmacêuticas e de Alimentos, Campus Capão do Leão, UFPel. CEP: 96160-000. Fone: (53)3275-7354. Email: bspastoriza@gmail.com

2 Autor. Doutor em Educação Científica e Tecnológica, Docente do Magistério Superior, Universidade Federal de Pelotas.Laboratório de Ensino de Química, Centro de Ciências Químicas, Farmacêuticas e de Alimentos, Campus Capão do Leão, UFPel. CEP: 96160-000. Fone: (53)3275-7354. Email: fabiosangiogo@gmail.com

${ }^{3}$ Autora. Mestre em Educação em Ciências e Matemática, Docente da Educação Básica, Escola Estadual Sylvia Mello. Laboratório de Ensino de Química, Centro de Ciências Químicas, Farmacêuticas e de Alimentos, Campus Capão do Leão, UFPel. CEP: 96160-000. Fone: (53)3275-7354. Email: lelatiti@yahoo.com.br

${ }^{4}$ Co-autora. Licenciada em Química, Universidade Federal de Pelotas. Laboratório de Ensino de Química, Centro de Ciências Químicas, Farmacêuticas e de Alimentos, Campus Capão do Leão, UFPel. CEP: 96160-000. Fone: (53)3275-7354. Email: karla.mcn@ hotmail.com

${ }^{5}$ Co-autora. Licenciada em Química, Universidade Federal de Pelotas. Laboratório de Ensino de Química, Centro de Ciências Químicas, Farmacêuticas e de Alimentos, Campus Capão do Leão, UFPel. CEP: 96160-000. Fone: (53)3275-7354. Email: sandrianevduarte@ gmail.com

${ }^{6}$ Co-autor. Licenciando em Química, Universidade Federal de Pelotas. Laboratório de Ensino de Química, Centro de Ciências Químicas, Farmacêuticas e de Alimentos, Campus Capão do Leão, UFPel. CEP: 96160-000. Fone: (53)3275-7354. Email: abiologianaturalviva@ gmail.com

${ }^{7}$ Co-autora. Licencianda em Química, Universidade Federal de Pelotas. Laboratório de Ensino de Química, Centro de Ciências Químicas, Farmacêuticas e de Alimentos, Campus Capão do Leão, UFPel. CEP: 96160-000. Fone: (53)3275-7354. Email: thaiibrede@ gmail.com

${ }^{8}$ Co-autora. Licencianda em Química, Universidade Federal de Pelotas. Laboratório de Ensino de Química, Centro de Ciências Químicas, Farmacêuticas e de Alimentos, Campus Capão do Leão, UFPel. CEP: 96160-000. Fone: (53)3275-7354. Email: nessalguimaraes@ gmail.com

${ }^{9}$ Co-autora. Licencianda em Química, Universidade Federal de Pelotas. Laboratório de Ensino de Química, Centro de Ciências Químicas, Farmacêuticas e de Alimentos, Campus Capão do Leão, UFPel. CEP: 96160-000. Fone: (53)3275-7354. vitoriaschiavondasilva@gmail.com 
Charlene de Paula ${ }^{11}$

Letícia Leal Moreira ${ }^{12}$

Jhonatas da Silva Nunes ${ }^{13}$

\title{
Resumo
}

Este texto se propõe a compartilhar a experiência denominada de cotutela, desenvolvida no Programa Institucional de Bolsas de Iniciação à Docência (PIBID) do grupo de Química da Universidade Federal de Pelotas (UFPel). Centrada numa aposta na coletividade e no trabalho colaborativo, trazemos aqui os diferentes olhares do grupo que estão imbricados no planejamento, desenvolvimento, realização e avaliação da proposta, articulando a ação de uma supervisora da área de Química da Escola Básica, dois coordenadores e um grupo que variou, durante os momentos aqui descritos, entre nove e doze discentes da Licenciatura em Química da UFPel. A partir do trabalho em cotutela, emergiram subsídios que reforçam os princípios do Programa, assim como também foram produzidos elementos que dão ênfase ao rompimento de uma solidão pedagógica e, destacadamente, a modificação das dinâmicas de sala de aula, trazendo uma interação colaborativa entre o grupo do PIBID e um protagonismo maior dos estudantes da Escola Básica ao sentirem-se mais acolhidos por um grupo de professores.

PALAVRAS-CHAVE: Cotutela. Formação de professores. Cooperação e colaboração. Ensino de Química.

\begin{abstract}
An experience named 'cotutela' developed by the group of the Programa Institucional de Bolsas de Iniciação à Docência (PIBID) of the Universidade Federal de Pelotas (UFPel) is shown and discussed in this text. Different group perceptions and views are presented and centered in the collective and collaborative work. A basic school chemistry teacher as a supervisor, two university coordinators and a number between nine and twelve university students formed the group. Cotutela was used to plan, develop, realize and evaluate the actions of the group in the school. From the cotutela approach and collaborative interaction of the group of teachers a rupture with the isolated pedagogical work and an improvement in the students' action are analyzed in this text.
\end{abstract}

KEYWORDS: Cotutela. Teacher training. Cooperative and collaborative work. Chemistry teaching.

\section{Resumen}

En este texto se propone compartir una experiencia denominada 'cotutela', desarrollada en el Programa Institucional de Bolsas de Iniciação à Docência (PIBID) del grupo de Química de la

${ }^{10}$ Co-autora. Licencianda em Química, Universidade Federal de Pelotas. Laboratório de Ensino de Química, Centro de Ciências Químicas, Farmacêuticas e de Alimentos, Campus Capão do Leão, UFPel. CEP: 96160-000. Fone: (53)3275-7354. Email: rodriguestavane1@gmail.com

${ }^{11}$ Co-autora. Licencianda em Química, Universidade Federal de Pelotas. Laboratório de Ensino de Química, Centro de Ciências Químicas, Farmacêuticas e de Alimentos, Campus Capão do Leão, UFPel. CEP: 96160-000. Fone: (53)3275-7354. Email: xaxahdepaula@gmail.com

${ }^{12}$ Co-autora. Licencianda em Química, Universidade Federal de Pelotas. Laboratório de Ensino de Química, Centro de Ciências Químicas, Farmacêuticas e de Alimentos, Campus Capão do Leão, UFPel. CEP: 96160-000. Fone: (53)3275-7354. Email: lealmleticia@gmail.com

${ }^{13}$ Co-autor. Licenciando em Química, Universidade Federal de Pelotas.Laboratório de Ensino de Química, Centro de Ciências Químicas, Farmacêuticas e de Alimentos, Campus Capão do Leão, UFPel. CEP: 96160-000. Fone: (53)3275-7354. Email: jhone.umes@ gmail.com 
Universidade Federal de Pelotas (UFPel). Centrada en una noción de colectividad y trabajo colaborativo, se presentan en el texto las diferentes miradas del grupo que están imbricados en el planeamiento, desarrollo, realización y evaluación de la propuesta. La acción del grupo articula una supervisora de la escuela básica con formación en Química, dos coordinadores y un grupo entre nueve y doce alumnos del curso de formación de profesores de Química de la UFPel. Con el trabajo de cotutela emergieran subsidios que refuerzan los principios del Programa, crean elementos que enfatizan el rompimiento de una soledad pedagógica y posibilitan condiciones de modificación de las dinámicas en el salón de clases. Estas acciones permiten una colaboración colectiva entre los actores del grupo PIBID y un protagonismo mayor de los estudiantes de la escuela básica, pues se sienten más acogidos por un grupo de profesores.

PALABRAS CLAVE: Cotutela. Formación de profesores. Cooperación y colaboración. Enseñanza de Química.

\section{INTRODUÇÃO}

Uma das características do trabalho coletivo e participativo da docência está na valorização de cada um dos olhares dos sujeitos que atuam em atividades didáticopedagógicas vinculadas ao contexto escolar. Obviamente, a noção de olhar passa, neste contexto, a adquirir um sentido mais ampliado que sua limitação física de ver (PASTORIZA, 2015). É assim que, no momento em que trazemos a noção de olhares, referimo-nos a distintos processos, como a articulação de diferentes sentimentos, expectativas, apostas, receios, experiências pregressas, compreensões (dos mais variados níveis) sobre as dinâmicas que se estabelecem no nível individual e que, na proposta desenvolvida, passam a constituir olhares do grupo de professores em formação inicial e continuada da área da Química, no Programa Institucional de Bolsa de Iniciação à Docência (PIBID) da Universidade Federal de Pelotas (UFPel).

Neste texto se utilizará de um recurso narrativo para produzir os argumentos que se dirigem à importância e presença de princípios gerais do PIBID na formação de professores, assim como aqueles que marcam um processo coletivo e colaborativo de trabalho compartilhado entre uma professora da Escola Básica, dois coordenadores e um grupo que variou entre nove e doze licenciandos da UFPel durante a realização das atividades descritas.

Objetivamos que as narrativas aqui trazidas, com e sobre a cotutela, promovam o encaminhamento e o compartilhamento com a comunidade escolar e universitária da presença de elementos que reforçam os princípios do PIBID, como: a construção de identidades docentes; a aproximação de discentes com o campo de atuação profissional; a qualificação das ações desenvolvidas na Escola e na Universidade, dentre outros. Ou seja, busca-se produzir elementos associados à docência, como a ênfase ao rompimento de uma solidão pedagógica (ISAIA; BOLZAN, 2008; ISAIA; BOLZAN; GIORDANI, 2007), à complementação e apoio entre os sujeitos no nível da prática realizada, a reflexão interativa entre os sujeitos a respeito das propostas que eram trabalhadas, a superação de medos e receios com base no apoio conjunto e, destacadamente, a modificação das dinâmicas de sala de aula, trazendo uma interação e protagonismo maior dos estudantes da Escola Básica ao sentirem-se mais acolhidos por um grupo de professores. 
O texto se organiza a partir de uma cena do contexto escolar e, posteriormente, traz relatos analíticos, de diferentes sujeitos (bolsistas, supervisora e coordenadores), que se relacionam com a cena apresentada e sua reflexão no contexto da cotutela. A argumentação se desloca em, basicamente, três momentos: o de realizar os primeiros contatos com a proposta da cotutela; o de sentir-se, estar e gostar da ação coletiva; e o de confrontar-se com as inseguranças, medos e receios da ação didática em sala de aula que, pelo grupo $e$ no grupo, é mediada. Para a construção coletiva apresentamos inicialmente uma cena genérica, a qual é seguida por três seções do texto que expressam grupos de relatos referentes aos olhares dos pibidianos e das pibidianas, da professora supervisora e dos coordenadores. Esses três momentos são, então, integrados na seção final que traz a produção coletiva de um olhar do grupo PIBID-Química para o trabalho e importância da cotutela.

\section{Uma cena, vários olhares}

O sinal de troca de período toca. Nesse momento, o pátio da escola, antes quieto, ganha uma vida impressionante. É justamente após o som do sinal que as portas das salas de aula são abertas e delas saem alunos e professores. Uns em busca de uma conversa com uma amizade que está na sala ao lado; outros, desejam que o tempo passe, querem descansar ou receber o calor do sol daquele dia. Mas, nesta escola, há algo diferente do que muitos já vivenciaram em outras escolas. Em meio a esses muitos que se deslocam em todos os sentidos, pelos pátios e salas, há um grupo distinto que acaba de sair de uma sala e já se dirige a outra. Sua diferença está em, justamente, não se projetarem nesse caminho de modo isolado como outros docentes, a exemplo daquele que saiu de uma sala e entrou em outra. Eles vêm como um grupo, e sua diferença é marcante, pois, mesmo que se dirijam à outra sala em um passo que os identifica como professores, seu caminhar, lado a lado, a empolgação, a respiração agitada e os olhos intensos os aproximam muito dos alunos que, ao soar o sinal, invadiram o pátio.

Ao ingressar na nova sala de aula esse grupo, em comparação ao outro docente que entrou em outra sala, ao invés de entrar um profissional em docência apenas, entram um, dois, três, quatro! Um deles já é reconhecido: é a professora titular, que já trabalha com a turma na escola. Contudo, os outros três elementos desse grupo são desconhecidos. Efetivamente, esse desconhecimento apenas estava por sua presença inicial na turma, pois o mesmo pátio da escola que foi invadido de gentes ao bater do sinal também já era o espaço de conversações sobre um grupo de diferentes professores que estavam atuando nas aulas de Química. Assim, essa presença de quatro integrantes, desconhecidamente conhecida, causa uma sensação de dúvida, interesse e curiosidade a respeito do que estariam ali fazendo juntos.

Dadas as apresentações e as conversações iniciais, o grupo se espalha pela sala. Inicialmente são retomadas as discussões das aulas anteriores para introduzir as novas. O grupo de professores que está na sala observa atentamente a professora titular e os alunos. Ora são dúvidas que os alunos trazem a alguém desse novo grupo de professores, ora alguém desse grupo é convidado pela professora titular a complementar as ideias, ora o grupo todo, está conversando com os alunos e, tanto individual, quanto coletivamente, trabalhando na proposta da aula do dia.

Inevitavelmente, como em todos os demais momentos, após certo tempo de trabalho o sinal soa. É mais um episódio que se encerra parcialmente, pois, embora a turma de alunos e os quatro do grupo tenham de encerrar a atividade daquele momento, 
sabe-se que na próxima aula de Química novamente se encontrarão. Feitas as despedidas, o grupo sai para o pátio e encontra-o dotado de vida. Com todas as dinâmicas que ali no pátio acontecem, uma em especial chama a atenção dos alunos que correm, conversam ou se encaminham às salas: o grupo dos quatro sujeitos encontra outro grupo, com três integrantes. Após uma conversa rápida, e já se encaminhando para a próxima sala de aula, o grupo dos quatro rapidamente se decompõe e recompõe, pois os quatro que estavam junto com a professora titular são substituídos pelos três que acabavam de chegar. O novo grupo de três sujeitos adentra na nova turma reiniciando as micro conversações entre grupo e alunos. A professora titular inicia os trabalhos da turma e as dinâmicas, ainda que totalmente distintas da última turma, repetem-se naquilo que as integra até o momento do próximo sinal.

O grupo, ao longo da semana é composto e decomposto conforme as turmas e os períodos se modificam, assim como, em um momento especial, esse grupo que ficou variando em quatro e três une-se totalmente, pluralizando-se em dezesseis sujeitos. Nesse momento, já não mais no espaço limitado de um período e outro entre os sinais, o grupo compartilha mais do que um relato: traçam-se diálogos, narrativas e reflexões que evidenciam a potência e a constituição de cada olhar durante o trabalho realizado, bem como as distintas cenas interpretadas e, assim, múltiplas situações, como se evidenciará na sequência, sobre as quais conversam e traçam estratégias para a ação docente.

\section{Um olhar de grupos de olhares: as pibidianas e os pibidianos na vivência da cena}

Como descrever tantos sentimentos e pensamentos vivenciados em um primeiro contato em uma sala de aula? Primeiramente um sentimento de deslocamento, sem saber como agir, mas, depois da turbulência, com mais calma, conseguimos visualizar a situação com mais clareza, o medo deu espaço ao prazer de lecionar. Como é gratificante olhar para aqueles rostinhos esperançosos, olhos brilhantes de cada um ali sentado em suas classes aguardando ansiosamente pelo desenrolar de cada aula.

\section{Olhares I}

Nosso grupo de três bolsistas, num primeiro momento, esperava a professora titular no lado de fora da sala de aula. Estávamos ansiosos, e nossa inexperiência e insegurança falavam mais alto, pois não conhecíamos a realidade que nos esperava. No instante em que a professora nos encontrou, entramos na sala de aula, e ela logo nos apresentou para a turma como Pibidianos do curso de Licenciatura em Química da UFPel, informando que nosso propósito em sala era contribuir com a professora no desenvolvimento de atividades e explicação de conceitos e, com isso, buscávamos ajudar os educandos e aprimorar nossa formação. Ela também explicou à turma que a acompanharíamos nos próximos meses. Num segundo momento, ainda um pouco envergonhados, nos apresentamos e conversamos com eles, a fim de que os alunos ficassem à vontade com nossa presença.

\section{Olhares II}

Entramos na unidade escolar e aguardamos o horário da aula na sala dos professores, éramos três pibidianos que entrariam em sala após o intervalo. No caminho para a sala de aula, no pátio da escola, encontramos os pibidianos que acabavam de sair da aula anterior. Conversamos um pouco sobre os conteúdos já trabalhados, da receptividade da turma e nos despedimos. Após uma conversa rápida, dialogamos sobre as perspectivas dos conteúdos, acerca do que trabalhar em sala e dos planos de aulas preparados. Vendo a empolgação de nossos colegas que acabavam de atuar em sala de 
aula, uma ansiedade inquietante se iniciava e, com ela, uma gama de questionamentos internamente passavam a ser feitos: quais serão os olhares que receberemos? Como será a nossa aula? Eles irão compreender? Precisamos não errar, mas, e se errarmos e algum educando perceber os nossos erros? Por onde iniciaremos a aula? Vou dizer meu nome primeiro? Qual será o nível de aprofundamento dos alunos? Será que vão fazer perguntas que eu não consiga responder?

Um ensaio mental de possíveis situações transbordava em pensamentos ao nos dirigirmos para a sala de aula. Ao adentrar nela, no momento em que somos apresentados pela professora titular, os educandos nos olham com um ar de curiosidade. Ela explica, assim como na turma anterior, nossa ação na escola. Similar aos demais colegas, após a professora titular iniciar a aula, aos poucos fomos agindo e atuando juntos, com ela e com os alunos da sala, e essa prática foi se repetindo e sendo qualificada pelas reuniões semanais, de modo que a cotutela se transformou em nosso projeto conjunto de formação no PIBID.

\section{Olhares III}

Com vivências diferentes, cada qual com suas dificuldades e facilidades, como já de costume, nosso grupo de bolsistas chegou à escola, numa segunda-feira, e se encontrou com a professora titular. Após conversas iniciais, nos direcionamos para sala de aula. Para a maioria das pessoas era uma segunda-feira normal, como todas as outras, mas para um grupo de pibidianas e pibidianos este dia da semana era muito diferente e especial, pois era o nosso acompanhamento em cotutela juntamente com a professora titular. Nós a esperávamos na sala dos professores, onde conversamos sobre o material daquele dia, o qual tínhamos planejado dias antes. Então, quando tocou o sinal, a professora veio em nossa direção e nos dirigiamos em conjunto até a sala de aula, ao encontro de nossos alunos. Até chegarmos na sala passávamos pelos corredores da escola, nos quais a maioria dos alunos aguardava pela chegada dos seus professores. Alguns conversando entre si, outros sentados no chão para pegar um solzinho no rosto, mas a maioria estava a descansar para a próxima aula que estava por acontecer. Os nossos alunos também estavam no pátio quando avistaram o nosso grupo. Eles entraram para a sala, e seus olhares eram curiosos e voltados para nós, ainda que já estivéssemos há algumas semanas com eles. Ainda estávamos um pouco envergonhados, então falamos: "Bom dia, turma!" e começamos a atividade daquele dia, explicando que faríamos uma lista de exercícios e que iríamos ajudá-los na resolução. Entregamos a cada um, exercícios sobre Química Orgânica referente aos conteúdos vistos em aula. A partir deste momento começamos a nos ver como docentes, e adquirindo uma confiança que até então não tínhamos.

Em uma dessas aulas em cotutela, após termos finalizado uma explicação, pedimos que os alunos fizessem os exercícios e, em um dado momento, um deles solicitou a ajuda de um dos pibidianos na resolução. Para nós foi gratificante o aluno ter solicitado a nossa ajuda e não da professora ali presente, constatando a nossa importância e contribuição com o aprendizado do aluno. No inicio de algumas aulas tínhamos a impressão de que nossa contribuição era mínima, mas quando conseguíamos a atenção deles, nem que fosse para ajudar na resolução de um simples exercício, algo dentro de nós mudava e o nosso desempenho começava a fazer sentido em nossas vidas.

Aos poucos nossos medos e ansiedades existentes no primeiro acompanhamento iam sumindo, e o que surgia era o prazer de estar ali. Começamos a nos sentir úteis, e a segunda-feira do acompanhamento começou a ser esperada com muita ansiedade. 
Depois de algumas listas, algumas aulas expositivas e dialogadas, então surgiu a "coragem e a ousadia" de levar algo além daquilo que eles estavam habituados. Então seria uma aula experimental, que planejamos com muito carinho e pensamos nos mínimos detalhes. Era uma prática sobre fermentação alcoólica. Chegamos no laboratório antes que eles. Sim! A aula foi no laboratório e foi o máximo! Quando começaram a chegar os alunos, foi aí que o coração disparou, e a ansiedade aumentou. Havia um medo de dar tudo errado, de eles não gostarem, e até não conseguirem aprender nada com aquela aula. Foi então que nós nos olhamos e, conversando entre olhares dissemos: "estamos prontos". A aula começou, os alunos estavam super curiosos, com olhares atentos, como se estivessem se perguntando: "o que é tudo isso?!". Conforme a aula foi se desenrolando, o medo foi ficando para trás, e a ansiedade também. A confiança foi tomando conta, e o sentimento começou a ser de gratidão, de amor por estar ali, por ver realmente qual a nossa importância ao sermos inseridos em uma sala de aula. Ao término da aula não foi aquele término de "Ufa, acabou!", mas sim, "como já acabou?! Precisamos fazer isso mais vezes!".

Em aula, os educandos passaram a nos reconhecer como profissionais, como professores. Bem, ao menos foi dessa forma que fomos chamados por eles. Juntos fomos percebendo as riquezas de uma dinâmica de sala de aula. E foi só observar o olhar da professora e dos companheiros que, algumas vezes, notamos pelas expressões faciais dos educandos, que talvez eles não estavam nos compreendendo em dados momentos. Tínhamos certeza disso quando o silêncio ecoava durante as explicações, assim como quando fazíamos a pergunta: Alguém tem alguma dúvida?

Um silêncio que não se sabe nunca se é de dúvida ou de vergonha, pairava, nessas horas, na sala. Mas, de repente, surgia uma perturbação: a dúvida de uma aluna quebrava o silêncio e, a partir dela, surgiam outras dúvidas. Nesse momento, a confiança, que por hora poderia ter sido abalada pelas expressões das faces dos educandos, retorna.

Após situações como essa, ao término da aula, um olhar de êxtase percorre o grupo de pibidianos. Para alguns, muitas vezes foi a primeira vez que atuavam em sala de aula, para outros, já se tratava de um hábito em sua formação.

$\mathrm{Na}$ atividade, ao levar em consideração as características e andamento dos estudos de uma turma que acompanhávamos em cotutela, apresentamos um plano de aula com a proposta de trabalhar o grupo funcional álcool. Essa proposta contemplou o uso de um vídeo sobre a industrialização e produção do álcool, uma problematização dos efeitos biológicos do etanol presente nas bebidas alcoólicas e consequências pelo seu consumo exagerado. Outras problematizações foram apresentadas durante exposição de informações que apresentavam o consumo de bebidas alcoólicas na adolescência, ingestão de álcool por condutores e leis de trânsito. Esse estudo, pensado em conjunto com o grupo PIBID, buscou valorizar situações relacionadas com as realidades cotidianas dos educandos, num movimento de possibilitar a compreensão aqueles temas e conceitos em sua própria realidade de vida. As atividades que foram realizadas permitiram o surgimento de diálogos sobre relações familiares e problemas pessoais. Aquele espaço de aula foi constituído, então, graças ao movimento conjunto e colaborativo da cotutela, que permitiu aos diversos educandos ter atenção do grupo de professores que estava em sala de aula, chamando-os para um diálogo e escuta atenta (FREIRE, 1996; SANTIAGO; NETO, 2011). Por exemplo, em outro momento, em uma nova situação, como estávamos em quatro em sala de aula, enquanto um pibidiano atuava regendo a aula (utilizando o quadro ou encaminhando atividades), os outros dois 
e a professora contribuíam com os educandos em suas dificuldades. Essa ação conjunta de atenção aos educandos e de articulação de um grupo docente teve impactos efetivos junto aos próprios educandos.

\section{Do olhar de si docente ao olhar docente atravessado por outros}

É chegado o momento em que muitas coisas novas aconteceriam, uma nova etapa se iniciava... Comigo estariam alunos/professores, o que eles seriam?... Meus colegas?... Como eu deveria agir? Em meio a tantos questionamentos, eu tinha uma certeza: preocupar-me com a formação deles! Preocupação!... Não era apenas com o grupo de alunos que estaria compartilhando a docência comigo... Minha grande preocupação também era os meus alunos!

Será que eles entenderiam? Será que os alunos/professores explicariam quantas vezes fosse necessário? Usariam uma linguagem clara? Como os meus alunos reagiriam? Será que iriam gostar desta nova experiência? Por mais que eu me preocupasse sobre como seria, se eles iriam ao dia da cotutela, se eles teriam se preparado, se eles se dedicariam, sempre acreditei no seguinte: "Vai dar certo!".

Segunda-feira... primeira cotutela de um grupo de pibidianas. Primeiramente encontrei uma delas: Lá estava ela... ansiosa... aguardando na porta da sala. Fiquei feliz ao vê-la, sorri e disse: "Fica tranquila porque vai dar tudo certo!". A seguir chegaram as outras pibidianas: As três foram à turma comigo, apresentei-as como alunas da Química, integrantes do PIBID e que estariam conosco nas aulas de segunda-feira. Os alunos da turma ficaram um pouco retraídos, eles observavam ao mesmo tempo em que eram observados. Para mim que observava ambos os grupos, via uma cena de duplo reconhecimento de espécie!... A Biologia explica! A atividade do dia era correção de exercícios. Nesta primeira aula elas observaram e faziam suas anotações. O sinal toca, hora da troca de turma. Vamos para uma turma menor, fiz a apresentação como na turma anterior, no entanto, esta segunda turma, as recebeu como se a etapa de reconhecimento já tivesse sido feita, foram muito receptivos, começaram a fazer perguntas, conversar, e isto deixou as pibidianas/professoras bem mais à vontade. Da mesma forma como na turma anterior era uma aula de correção de exercícios, porém nessa, elas me ajudaram na correção, indo de classe em classe.

Terça-feira... primeira cotutela de outro grupo de pibidianas. Elas estavam claramente ansiosas, um pouco nervosas e preocupadas com o que fariam... disse para elas que ficassem tranquilas e bastava observarem a aula! Fiz a tradicional apresentação para os meus alunos. Da mesma maneira que no dia anterior, elas observavam e anotavam, enquanto meus alunos também as observavam. Assim que encerrou este período, fomos para a outra turma e a maneira de proceder, foi a mesma. Este grupo foi um pouco mais retraído em suas primeiras cotutelas.

Por fim, chega a quinta-feira, este seria o meu terceiro dia de cotutela! Neste dia estariam comigo um grupo de três pibidianos. Dos três acompanhamentos, este foi o que mais me surpreendeu, pois eles atuaram desde o primeiro momento como cooperadores no desenvolvimento das aulas! Este foi o grupo que, apesar do nervosismo e ansiedade, demonstrou maior tranquilidade e sentiu-se mais à vontade com os alunos da escola.

A experiência de estar compartilhando a docência foi muito importante para mim, e assim divido este processo em três etapas:

Troca entre professora e pibidianos/professores: 
Esta foi a etapa em que estive mais centrada na formação dos futuros professores, em que minha preocupação se dividia entre eles e meus alunos. Foi o período em que revisei seus materiais, auxiliei na sua elaboração, bem como tirei suas dúvidas, orientando-os sempre que eles me solicitavam.

Nessa etapa também aprendi com os docentes em formação, pois tive a oportunidade de participar do desenvolvimento de seu trabalho e de sua docência, além de termos espaço para posteriormente discutirmos sobre o que foi desenvolvido, buscando formas de superarmos as fragilidades. Nesse sentido:

As escolas, como espaços de reconstrução do conhecimento e reconstrução cultural, teriam melhores condições para cumprirem o seu papel institucional se os seus atores participassem dessas criações, as desenvolvessem em ação conjunta e conjuntamente analisassem os resultados das práticas de sala de aula. (GAVIOLI, 2005, p. 32).

Além da formação dos futuros professores, minha preocupação também era com a aprendizagem dos meus alunos. Mas com o passar do tempo, pude perceber que agora não havia apenas o meu olhar atento sobre eles, mas também os olhares atentos de um grupo de três a quatro professores que formávamos, o que acabou contribuindo com a sua aprendizagem. Conforme as palavras de Hoffmann (2014, p. 53): "É preciso salientar que os percursos da aprendizagem são individuais e diferenciados, e que as propostas pedagógicas irão mobilizar os alunos de jeitos inusitados. Não há como se observar todos os alunos, todo o tempo e em todas as situações planejadas", mas o fato de um grupo de professores estarem atentos a um grupo de alunos torna essa observação mais intensa, mais detalhada e com diferentes olhares, proporcionando assim mais oportunidades de contribuir com a aprendizagem.

Troca entre professora-supervisora e professores-coordenadores:

Estar envolvida na formação de um grupo de futuros professores é uma experiência que tenho pouca prática. E aqui destaco a importância do apoio sempre constante dos coordenadores do nosso grupo, os quais estão sempre atentos e dispostos para contribuir, colaborar e orientar nesta caminhada que estamos percorrendo. Assim:

\begin{abstract}
Esse não é um caminho a se percorrer solitariamente. Não é fácil aventurar-se sozinho ao desconhecido. Exige preparo e apoio. Não basta querer fazer diferente. O professor precisa de mediadores para o seu desenvolvimento profissional. Pode reconhecer limites, expressar dúvidas, não saberes, mas ultrapassá-los não é simples. Além de compartilhar a prática, é preciso o avanço teórico a partir de desafios significativos com colegas e supervisores, com alguém que exerça o papel de interlocutor nessa busca, nessa construção, que possa orientá-lo naquilo que sabe que precisa fazer, mas que ainda não sabe como fazer (HOFFMANN, 2014, p. 45).
\end{abstract}

É importante que estejamos sempre avaliando a nossa prática docente e reorientando-a sempre que necessário. Por vezes, acabamos agindo de maneira que nos parece a melhor forma de desenvolvermos nossas ações, no entanto, podemos nos perceber em constante processo de formação sempre que temos a oportunidade de aprender e sermos formados por outros professores, através de suas práticas, experiências e compartilhamento conosco. Assim:

Podemos repetir muitas vezes a mesma coisa sem nos darmos conta do que estamos dizendo. Mas quando ouvimos isso de outras pessoas, interpretamos 
de outra forma, pois elas, ao falar de suas práticas, podem nos ajudar a compreender o que estamos fazendo em nossas salas de aula. (HOFFMANN, 2014, p. 53).

\title{
Minha prática:
}

Estar compartilhando/dividindo a sala de aula com outros professores não é uma prática que se faça sem receios, dúvidas, inquietações ou inseguranças. Afinal, estamos abrindo um espaço que é nosso, para o novo, para o desconhecido. No entanto, é uma oportunidade de também estar em formação. Não uma formação inicial de professores, mas sim, uma formação continuada. Sempre que nós, professores em exercício, abrimos espaço em nossas salas de aula para futuros professores, também estamos abrindo espaço para reorientarmos nossa práxis. De acordo com Maldaner (1999, p. 88): "Esses (os professores) abrem seus flancos, mesmo que se sintam invadidos em seu espaço profissional, tentam colaborar para, em cima disso, tentar melhorar a sua prática profissional".

Esta experiência da docência compartilhada, desenvolvida na cotutela, proporcionou-me refletir sobre a minha prática docente, além de repensar alguns olhares e compreender novas formas de trabalho em grupo. Conforme nos fala Meirieu:

\begin{abstract}
Na verdade, um "bom conceito" é precisamente aquele que esclarece minha experiência, que me permite organizá-la, compreendê-la, dominá-la, e não aquele que me impõe de fora renunciar a ela ou que complica artificialmente os meus problemas. Um "bom conceito" não se substitui a um saber anterior, mesmo que desordene minhas representações: dá forma a minha experiência, torna a realidade mais assimilável e permite agir sobre ela (1998, p. 27).
\end{abstract}

\section{Um olhar que não está presente, mas que se constitui no diálogo}

As cenas descritas no início deste texto, assim como as relatadas pelos pibidianos e pibidianas e pela professora supervisora, constituem um grupo de acontecimentos formativos que perpassaram as ações do PIBID-Química. Ainda que nós, coordenadores, não estivéssemos presentes nelas, no momento em que as dinâmicas se estabeleceram no processo de cotutela na escola, há a produção de um trabalho coletivo e formativo. Ainda que não tenhamos nosso olhar presencial, ele vai sendo constituído no diálogo que vamos traçando nos encontros sistemáticos e semanais que temos com o grupo. Isso implica em dizer que, mesmo não estando fisicamente presentes, o processo compartilhado no grupo nos permite, também, vivenciar e tornar a cotutela uma experiência (LARROSA, 2002) em nossa formação.

É por essa via de experiência coletiva que todo o processo de construir a proposta da cotutela se deu em colaboração entre nós, a supervisora e os discentes. A todo momento, as ações foram pautadas na expectativa de aproximar as ações do PIBID com a docência, tendo em vista relatos expressos pelos bolsistas ao longo das reuniões e planejamentos que diziam serem intensas e aprendentes as atividades de maior contato com a escola, com os professores e com os estudantes. Sob o aspecto teórico, a cotutela emergiu da aposta na formação coletiva e cooperativa entre discentes, supervisora e coordenadores da área da Química, ancorada numa ideia de formar-se ao formar (WARSCHAWER, 2001), bem como na busca por maior aproximação com a realidade escolar e a atuação docente, com vistas a qualificar compreensões pedagógicas e/ou epistemológicas com e sobre a docência, ou seja, uma maior percepção sobre a 
complexidade das práticas e teorias que permeiam a escola e o trabalho docente (MALDANER, 2003). Assim,

[...] há o pressuposto de que a cotutela constitui um tempo e espaço em que os pibidianos podem: vivenciar atividades de iniciação à docência; vivenciar os espaços da escola, da sala de aula, de turmas do Ensino Médio; compartilhar a docência com a professora supervisora, ao interagir com os estudantes, ao pensar, refletir e propor atividades de ensino, com trabalho coletivo entre bolsistas, orientação da professora supervisora e coordenadores de área. (SANGIOGO; AZEVEDO; PASTORIZA, 2016, p. 2).

Desse modo, ao buscarmos, como coordenadores, atuar no conjunto do grupo do PIBID com as cotutelas, percebíamos que ela poderia contribuir com a maior inserção dos discentes em seu campo profissional (a escola), bem como ser elemento de realização de processos formativos coletivos a nós, à professora supervisora e ao grupo de pibidianos e pibidianas.

É nesse sentido, então, que percebemos os olhares e relatos dos bolsistas e da supervisora serem constituidores e promotores de ações por nossa parte, da coordenação, resultando em movimentos coletivos que também têm efeitos nas atividades que são solicitadas aos bolsistas e à supervisora, ao mesmo tempo que nós (coordenadores) somos constituídos pelos relatos e diálogos experienciados no grupo e pelo grupo.

É importante ressaltar que os momentos iniciais de propor o trabalho em cotutela ao grupo foram dotados de inseguranças e desafios. Isso porque, coletivamente, os próprios olhares a respeito do processo ainda não estavam constituídos, de modo que tal relação com o "desconhecido" gerava anseios que, somente em grupo, podiam ser trabalhados, mediados e problematizados. Nas discussões iniciais, antes do primeiro contato com as turmas, os olhares e as falas dos licenciandos demonstravam angústias, medos, vontades, incertezas, dentre outros sentimentos relativos à ação docente num processo desconhecido. Era possível perceber a criação de imaginários que retratavam a ansiedade e expectativa de suas ações. Ao se colocarem como professores no contexto da cotutela, os pibidianos e as pibidianas tentavam planejar atividades, imaginavam cenas, explicações ou perguntas possíveis que poderiam emergir quando estivessem juntos aos estudantes e à professora supervisora em sala de aula. Essa conjuntura nos preocupava, coordenadores e supervisora, pois, tanto víamos esse momento de organização da cotutela como potente no que tange à ação formativa do PIBID, quanto trazia o receio de que os anseios, se não trabalhados de modo satisfatório, poderiam ser constituidores de alguns traumas ou decepções dos que iniciavam suas primeiras imersões em sala de aula. Ou seja, enquanto coordenadores e supervisora, tentávamos mediar e dialogar sobre as angústias expressas ao longo das reuniões de grupo e orientações a respeito da cotutela e sua organização. Nesse sentido, evidenciávamos certa tensão do grupo para o momento de vivenciar o novo e as dinâmicas da escola a partir de um arranjo ainda não experienciado por todos nós, de modo que o grupo, em seu reconhecimento enquanto tal, foi se autogestando, mediando e aportando diferentes olhares na constituição de seu olhar coletivo no desenvolvimento da cotutela.

Assumidos os compromissos coletivos com a proposta formativa da cotutela, já nos momentos iniciais das ações desenvolvidas percebemos que os primeiros relatos dos pibidianos eram, em maioria, relativos a uma remoção ou superação de alguns anseios referentes ao estar e atuar em sala de aula, principalmente no que tange ao modo como os estudantes da escola e a supervisora do PIBID (e professora da turma) reagiriam. No 
entanto, outros continuavam ansiosos e ainda não se sentiam confortáveis para falar, propor atividades ou se colocar como um dos professores em ação com a turma. Ao ter relatos angustiados de bolsistas, percebemos um movimento de afirmação do caráter de grupo e de ação coletiva quando evidenciamos que, nesse processo, a cotutela permitia que aqueles e aquelas bolsistas mais experientes ou desinibidos confortassem e auxiliassem os colegas menos experientes. Nesse movimento formativo, a docência coletiva ia se constituindo no momento de nós coordenadores e da professora supervisora propormos que os pibidianos e pibidianas realizassem pequenas explicações para a turma acompanhada, assim como a todo o momento, e constantemente, se realizava um estudo e planejamento das aulas antes de sua efetivação. Nesse sentido, bolsistas, supervisora e coordenadores compartilhavam e produziam os planejamentos de atividades antecipadamente, constituindo-as a partir de uma leitura conjunta do que era proposto. Esse processo pôde construir um ambiente de confiança no grupo, de modo que permitia que a supervisora e os coordenadores estimulassem a participação e a produção dos bolsistas de atividades inovadoras em sala de aula, uma vez que a própria noção de "erro" ou "falha" de uma proposta didática pôde ser problematizada e revista.

Ao perceber o espaço da cotutela com um grande potencial formativo, buscamos, junto da professora supervisora, estimular a construção de relatos escritos das atividades, como modo de que se pudesse identificar pontos positivos e negativos da cotutela à formação docente. Entretanto, estes tendiam a ser muito descritivos e com pouca reflexão. Contrariamente às produções escritas, os relatos orais das reuniões eram muito mais ricos em reflexões, trazendo elementos que versavam sobre a contribuição da cotutela à formação dos bolsistas, supervisora e coordenadores. Um desses movimentos de relatos orais, realizados nas reuniões de grupo e mediados por uma dinâmica em que tinham de expressar (escrevendo no quadro) palavras que representassem a experiências das cotutelas, foi muito proveitoso ao grupo e, inclusive, publicizado em evento (SANGIOGO; AZEVEDO; PASTORIZA, 2016).

Nesse contexto, percebemos que o novo, no sentido da inovação ${ }^{14}$, na formação docente ou na prática de atividades planejadas para o ensino médio, para bolsistas, supervisora ou coordenadores pode ser algo introduzido de diferente do que vem sendo realizado. O contexto inovador das cotutelas aos bolsistas, professora supervisora e professores coordenadores, incitou novos modos de organizar, planejar e atuar e, consequentemente, fez pensar, estudar e refletir sobre conteúdos, concepções e/ou práticas individuais e coletivas do grupo envolvido.

Os relatos das experiências e das percepções constituem a docência compartilhada por esse grupo, interferindo nos planejamentos para além da cotutela. Nós, coordenadores, não estamos presentes na cotutela, mas percebemos que, conjuntamente, interferimos e somos perpassados pelos olhares dos demais sujeitos que compõem o grupo e, consequentemente, com base nessa realidade da escola e dos múltiplos sentimentos e experiências docentes, podemos auxiliar na (re)condução, (re)produção e (re)construção das orientações no grupo do PIBID e no contexto do Ensino Superior no qual atuamos - a exemplo dos projetos de pesquisa, ensino e extensão, ou em componentes curriculares que envolvem os estágios supervisionados e as práticas como componente curricular que envolvem o curso de Licenciatura em Química. Nesse sentido, os olhares da cotutela nos formam e transformam no

\footnotetext{
${ }^{14}$ No dicionário Aurélio, a palavra é conceituada como: "1 - Introduzir novidades em.; e 2 - Renovar;
} inventar; criar.”. Disponível em: 〈https://dicionariodoaurelio.com/inovacao〉. Acesso em: 30 Mar. 2017. 
movimento formativo que a ação do PIBID traz a nós, coordenadores, à supervisora e bolsistas.

\section{De olhar a olhares: a coletividade na produção da cotutela e a formação docente}

As diferentes seções acima evidenciaram olhares distintos que se formaram no processo de constituição da proposta da cotutela no grupo do PIBID-Química da UFPel. Ainda que irregulares em sua redação, ênfases e movimentos descritos, entendemos que essa diferença de percepções permite ao nosso grupo constituir, a partir de múltiplos olhares, um modo de percebermos e nos formarmos coletivamente a partir da cotutela.

Efetivamente, a proposta do PIBID emerge enquanto aposta de aperfeiçoamento e valorização da formação de professores para a Escola Básica (CAPES, 2017). Todavia, entendemos que compreender o significado e abrangência do que se constitui enquanto universo formativo de professores para a Escola Básica implica em reconhecer que ações que colaborem nesse sentido necessitam colocar em marcha movimentos formativos conjuntos entre Escola Básica e centros de formação, como as Faculdades e Universidades. É nesse sentido que apostamos na cotutela como um movimento que colabora intensamente à qualificação e valorização desse cenário. Distinta de outros processos formativos do Ensino Superior, como os estágios ou práticas de ensino, assim como diferente de outras ações de formação continuada, como cursos, a cotutela promove uma formação coletiva de discentes da licenciatura e de docentes atuantes na Escola Básica e formação superior (Universidade), ao movimentá-los conjuntamente no planejamento, realização e avaliação de práticas de salas de aula. Mais do que isso, promove um movimento coletivo de compartilhamento do espaço de sala de aula e de apoio conjunto entre professores e professoras atuantes e em constante formação movimento este que é tão distinto e que se coloca na contramão de políticas atuais de precarização da docência, de isolamento do professorado e de desatenção aos sujeitos escolares.

A importância da presença de um grupo de professores em sala de aula se evidenciou ao longo de todo o processo, pois tanto nos momentos de planejamento quanto nos de ação docente não nos víamos mais sozinhos ou isolados (ISAIA; BOLZAN, 2008), mas em um grupo que se auto regula, auxilia e media.

Para ministrar as aulas, o movimento de cotutela propiciou uma interação entre o grupo, com o papel de docente e com os demais alunos. Na presença de um ambiente calmo, o grupo se dividia dentro da sala com o intuito de estabelecer aproximação dos estudantes, reforçando nossa intenção de auxiliá-los, em busca de entender quais dúvidas precisavam ser sanadas e quais conceitos necessitavam ser mais adensados. Sem dúvidas, se não tivéssemos essa ação conjunta, integrada e colaborativa, tais atenções, ambiente de trabalho e discussões a respeito de quais estratégias desenvolver não teriam os efeitos intensos e significativos nas nossas formações e nas dos educandos - o que nos reafirma a validade e destaque das ações em cotutela.

Isso tudo nos leva a refletir sobre a importância de trabalhar em grupo e da dinâmica do PIBID na inserção dos alunos da graduação na preparação de atividades de ensino, na superação de dificuldades e na formação para futura vida docente. Sem esta experiência que o PIBID nos proporciona, seria possível ter essa visão tão ampla da profissão? Temos alguns pibidianos do primeiro semestre já envolvidos com o sistema de ensino na escola, no intuito de evoluir seus conhecimentos, de aprender, de conhecer a rotina de um professor. Como é importante essa oportunidade de estar na sala de aula 
como docente, mesmo que por alguns minutos, ainda sendo discentes e tendo todo o suporte de uma professora atuante e experiente na Escola Básica e de dois professores do Ensino Superior. Isso fez emergir a compreensão de que juntos somos capazes.

Nossa aposta na cotutela, que segue na atualidade de nosso trabalho, mas que sempre se reconstrói nas ações que desenvolvemos no Programa, reforça-se nos aspectos profundamente aprendentes que ela traz consigo, principalmente relativos ao formar ao formar-se e ao não percebermo-nos solitários em sala de aula, mas sempre amparados por um conjunto de sujeitos com os quais nos identificamos, apoiamos e, coletivamente, construímos um olhar e diversos olhares relativos à formação que sustenta nossas ações, perspectivas, planos e esperanças.

\section{REFERÊNCIAS}

CAPES (Brasil). Pibid - Programa Institucional de Bolsas de Iniciação à Docência. 2017. Disponível em: <http://www.capes.gov.br/educacao-basica/capespibid/pibid>. Acesso em: 20 abr. 2017.

FREIRE, Paulo. Pedagogia da autonomia: saberes necessários à prática educativa. São Paulo: Paz e Terra, 1996.

GAVIOLI, Aparecida de Fátima. Um olhar sobre o currículo de formação de professores: transformando atitudes em prática docente de inclusão. Revista da UNESC/CACOAL/RO, Ano 2, n. 4, 2005.

HOFFMANN, Jussara. O jogo do contrário em avaliação. 9.ed. Porto Alegre. Mediação. 2014.

ISAIA, Silvia; BOLZAN, Dóris; GIORDANI, Estela. Movimentos contrutivos da docência superior: delieando possíveis ciclos de vida profissional docente. In: $30^{a}$ Reunião Anual da ANPED. Anais... Caxambu, MG, 2007.

ISAIA, Silvia; BOLZAN, Dóris. Compreendendo os movimentos construtivos da docência superior: construções sobre pedagogia universitária. Revista Linhas Críticas, v.14, n.26, p.43-58, 2008.

LAROSSA, Jorge. Notas sobre a experiência e o saber da experiência. Revista Brasileira de Educação, n. 19, p.20-28, 2002.

MALDANER, Otavio. A pesquisa como perspectiva de formação continuada do professor de química. Química Nova, v. 22, n.2, 1999.

MEIRIEU, Philippe. Aprender... sim, mas como? 7ed. Porto Alegre: Artmed, 1998.

PASTORIZA, Bruno dos Santos. Educação Química em discurso, ou sobre um modo de olhar para a prática da Educação Química. 2015. 374 f. Tese (Doutorado em Educação em Ciências), Universidade Federal do Rio Grande do Sul, Porto Alegre, 2015.

SANGIOGO, Fabio; AZEVEDO, Aurélia; PASTORIZA, Bruno. A cotutela na formação de pibidianos da área da Química da UFPEL: olhares da supervisão e coordenação do subprojeto. In: VI Encontro Nacional das Licenciaturas, V Seminário Nacional do PIBID, V Encontro Nacional de Coordenadores do PIBID e X Seminário Institucional PIBID PUCPR. Anais... Curitiba: PUCRS, 2016. 
SANTIAGO, Maria Eliete; NETO, José Batista. Formação de professores em Paulo Freire: uma filosofia como jeito de ser-estar e fazer pedagógicos. Revista e-curriculum, São Paulo, v.7, n.3, dez., 2011, p. 1-19

WARSCHAUER, Cecília. Rodas em rede - oportunidades formativas na escola e fora dela. São Paulo: Editora Paz e Terra, 2001.

Recebido em: 20-06-2017

Aprovado em: 20-07-2017 